\title{
PERCEPTUAL CONSTANCY AND CONTEXTUAL ENHANCEMENT
}

\section{CONSTANCIA PERCEPTUAL Y MEJORAMIENTO CONTEXTUAL}

HERIBERTO AVELINO

Max Planck Institute for Evolutionary Anthropology, Germany.

heriberto_avelino@eva.mpg.de

\begin{abstract}
The perception of the acoustic world surrounding us very often is different from its physical properties. Our mental representation of the sounds that we are exposed to are not in a one to one correspondence with the sounds we sense. Auditory objects and their environments are categorized and loaded in memory so that recognition of complex dynamic scenes are perceived optimally. Precise identification of voices and linguistic objects are crucial for effective communication. However, the normal context of hearing contains multiple, competing and noisy sources. In such disadvantageous conditions the identity of the percepts is more efficient if they are stored in memory. The results of the present study offer experimental evidence that high-level cognitive processes might constrain basic auditory mechanisms involved in identifying phonemic tone to guarantee perceptual constancy. The results showing a better identification of tones in contexts that are inveresely proportional to their frequency support the idea that peripheral auditory processing enhances the identification of the tones by a general function of contextual contrast.
\end{abstract}

Keywords: Speech perception, experimental phonology, tone languages.

\section{RESUMEN}

La percepción del mundo acústico que nos rodea es a menudo diferente de sus propiedades físicas. Nuestra representación mental de los sonidos a los que estamos expuestos no están en una correspondencia unívoca con los sonidos que sentimos. Los objetos auditivos y sus contextos son categorizados y acumulados en la memoria de forma tal que el reconocimiento de escenas dinámicas complejas son percibidas óptimamente. La identificación precisa de voces y objetos lingüísticos son cruciales para la comunicación efectiva. Sin embargo, el contexto normal de la escucha contiene fuentes múltiples, con ruido y en competencia. En estas condiciones de desventaja la identidad de los perceptos es más eficiente si son almacenados en la memoria. Los resultados del presente estudio ofrecen evidencia experimental de que procesos cognitivos de nivel alto pueden restringir los mecanismos auditivos básicos involucrados en la identificación del tono para garantizar una percepción constante. Los resultados que muestran una mejor identificación de tonos en 
contextos que son inversamente proporcionales a su frecuencia apoyan la hipótesis de que el procesamiento auditivo periférico mejora la identificación de los tonos a través de una función de contraste contextual.

Palabras claves: Percepción del habla, fonología experimental, lenguas tonales.

Recibido: 25-11-2009. Aceptado: 19-04-2010.

\section{INTRODUCTION}

The effect of the context in the perception of brightness is a well known phenomena in the literature of visual perception research. Figure 1 illustrates the effect of the relative perception of simultaneous brightness contrast. In general, the inner squares are perceived as having different degress of darkness: In the upper panel the leftmost square is perceived as the darker and the rightmost as the lighter. However, as evident in the lower panel, the squares are identical.
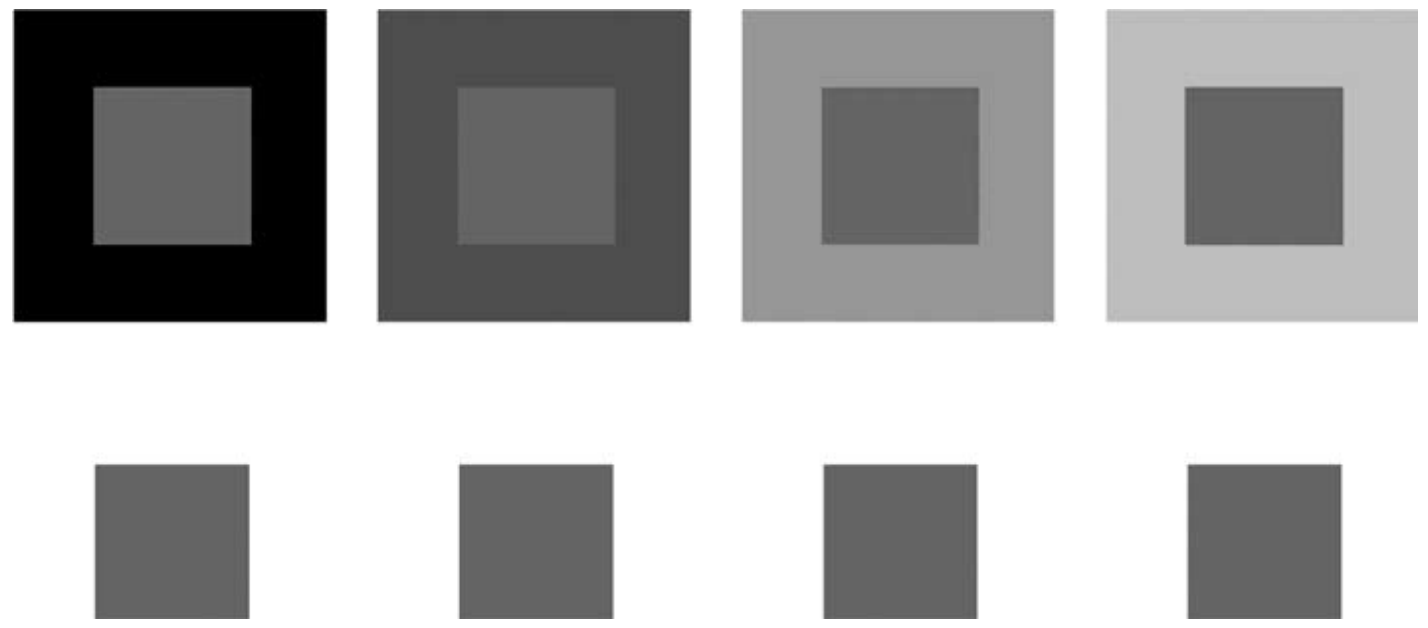

Figure 1. Relative perception of brightness depends of the luminance relations of different stimuli.

There is strong evidence supporting a psychophysical explanation that the effect is produced by inhibitory reactions in areas of the retina triggered by the level of luminance exitation in adjacent areas (Adelson, 1993; Hartline, 1967; Hartline, Wagner and Ratcliff, 1956). The effect illustrates the fact that perception of brightness is not a direct function of the physical properties of the stimuli, but that the perception of different shades of grey is partially computed by the visual system taking into account the larger context of reference.

Equivalent phenomena to the lateral inhibitory visual effect might be found in the auditory domain (Massaro, 1987; Schouten, 1987). In general, listeners 
can make subtle judgments about the relative magnitudes of auditory objects; however, only rarely make judgments of the absolute magnitudes of speech stimuli. In a pioneering paper, Ladefoged and Broadbent (1957) showed that the relative size of the surrounding context affects the perception of vowel quality. However, in later research Ladefoged (1989) showed that the effect occurs only with poor synthesized speech stimuli. Notwithstanding, the literature on cross-modal as well as speech perception phenomena confirms the influence of the context in the perception of linguistic stimuli (Fowler and Dekle, 1991; Grosjean, 1980; Holt and Lotto, 2002; Lotto and Kluender, 1998; Lotto, Sullivan and Holt, 2003; McGurk and MacDonald, 1976; Warren and Warren, 1970). Thus, although previous studies in visual and speech perception have shown that the context can affect the way in which subjects perceive otherwise identical stimuli, there are jus a few studies addressing the influence of the context in the perception of lexical tone. The present study endeavors to contribute to the body of research on the topic by investigating the role of the larger context in the perception of phonemic pitch in Yalálag Zapotec, a tone language.

\section{BACKGROUND}

Yalálag Zapotec is an Oto-Manguean language spoken in Villa Hidalgo, in the Municipality of Villa Alta, Oaxaca, Mexico. According to the Mexican census for the year 2000, there were 2115 people residing in Yalálag (INEGI, 2001). There are Yalaltec settlements in different cities in Mexico and the US, especially Los Angeles, CA. However, the number of speakers living outside of Yalálag is undetermined. The language described here represents the speech of Yalálag immigrants in the US. All the consultants were born and raised in Yalálag. The immigrants have spent an average of 10 years in the US, where they learned English, and improved their Spanish. Nevertheless, YZ is their native, first language, which moreover they use on a daily basis in different contexts (at home, with co-workers, or on the phone with family and friends, for example).

Yalálag Zapotec has three tones: high, low and falling. A number of factors indicate the phonemic status of the three tones, and especially that of the contour tone. First, they enter in contrastive relations, so that there are minimal pairs for tone. Second, none can be derived from one of the other two in the lexicon; and third, the three tones are the maximum of tone contrasts found in the tone system. Additional contours -falling and rising- and tone adjustments, such as upstep and downstep, might arise as the result of morphological and intonational processes. High and low tones are essentially realized as level, although slight variations (either rising or falling) can occur towards the end. Nevertheless, these variations are non-phonemic. Falling tone is characterized by a prominent slope 
that occupies the whole range of the tonal space, i.e. it starts at frequencies closer to those of high tone and falls down until reaching the ranges of low tone. Figure 2 below illustrates the F0 contours of a representative triple contrast between high, low and falling tones in modal syllables. The high and low tones illustrated by /já/ 'temescal' (traditional sweathouse) and /jà/ 'bell' have a fairly steady frequency, in contrast with the significant falling trajectory observable in / jâ/ 'cane'.

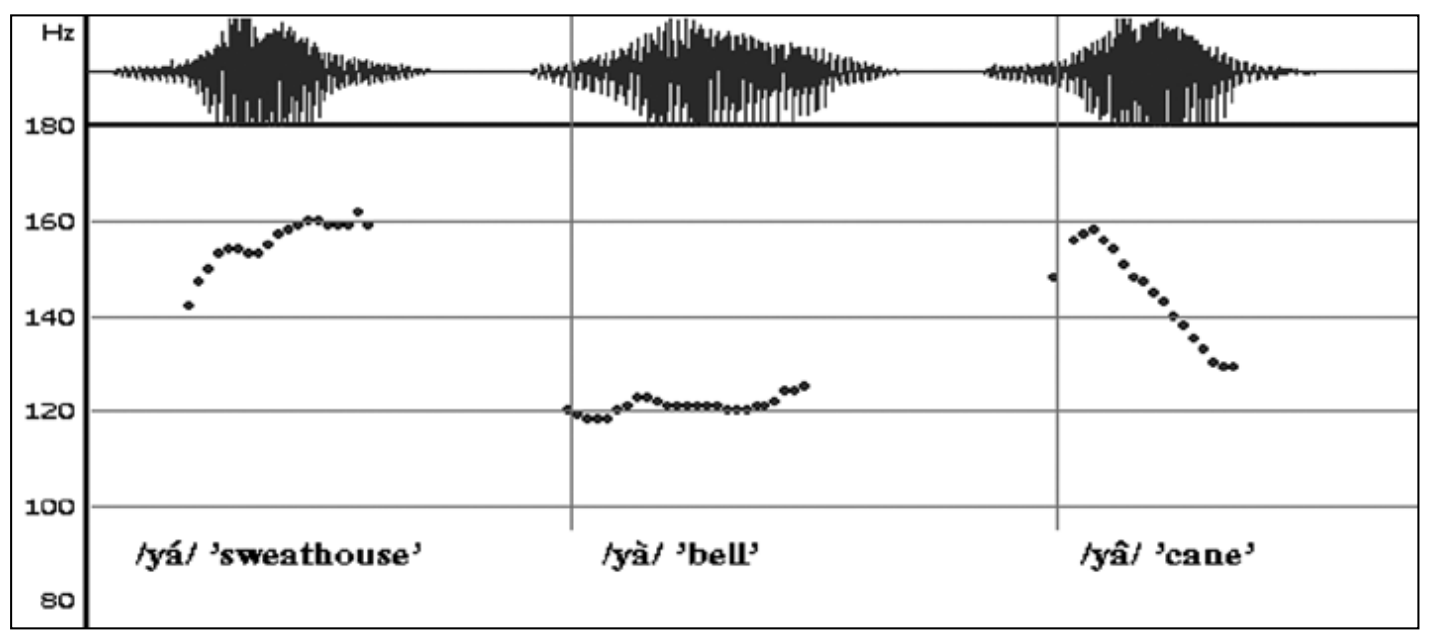

Figure 2. Pitch tracks of the of the words /já/ 'sweathouse', /jà/ 'bell' and /jâ/ 'cane' illustrating the contrast between high, low and falling tone.

\section{METHODS}

\section{Subjects}

Ten subjects native speakers of YZ participated in this study. Seven were female and three were male. Their ages ranged from 15 to the 60's. None reported antecedents of abnormal hearing. Eight subjects have lived in the United States between 10 and 20 years, and two for less than a year. All of the participants in this study grew up speaking only Zapotec at home, and still is their dominant language at the time of the experiment.

\section{Stimuli}

The stimuli used in the experiment was generated as follows. A male speaker with no antencedents of hearing or speaking disabilities was recorded producing 10 samples of the sentence Bnèchj bi dì'llên yèlò' gànà' _ 'Guess what word did you hear here _'. The sentence was chosen because of its pragmatically plausibility and because it makes use of the three phonemic tones, a high tone 
in the word $b i$, a falling and a low tone, respectively, in the last and initial syllables of the words dìllên yèlò'. Five repetitions of 12 words corresponding to 6 minimal pairs of tone were recorded. The speaker and the experimenter selected the 'best' exemplars among the sentences and words to be used in the experiment based on their overall naturaleness and tone stability. The speaker's normal frequency ranged from $170 \mathrm{~Hz}$ to $130 \mathrm{~Hz}$. It was confirmed that the mean frequency values of the high and low tone words occupied, respectively, the ceiling and floor limits of his range. Six resyntehsized versions of the prompt sentence were produced by modifying the F0 of the original sentence. Three sentences with higher frequencies and three with lower frequencies than those of the unmodified sentence were produced in increasing/decreasing ratios in the order of 50,25 , and $15 \%$ with respect to the $\mathrm{F} 0$ of the unmodified sentence. The intensity of the sentences and the target words were normalized to $70 \mathrm{~dB}$ (SPL). Manipulation and resynthesis of the stimuli were produced with the Praat program (Boersma and Weenink, 2005). Figure 3 shows the pitch tracks of the sentences so generated and presented to the subjects. The leftmost utterance corresponds to the stimuli with the highest frequency. It has a range of 6.40 (maxima) and 5.20 (minima) ERB, which corresponds to an increasing of 50\% higher than the range of the normal or unmodified sentence frequency, which in turn is in the range of $4.70-3.55 \mathrm{ERB}$. The rightmost utterance is the lowest end of the continuum; its values range from 2.60 to $1.90 \mathrm{ERB}$ and correspond to a decreasing of $50 \%$ with respect of the unmodified sentence. Thus, other things being equal, the seven versions of the prompt sentence were different only in the F0 values. Particular care was taken that the sentences produced a fair impression of natural, spontaneous speech. The sentence with the lowest frequency sounded natural but distorted to some extent. The target words themselves were not modified but had the pitch of the original recording.

\section{Procedure}

Subjects were told they would be participating in an experiment in which they would hear words that might differ only in tone. The experiment consisted of one block of 84 randomized items. The block contained the seven variations of a sentence prompting each of 10 words illustrating the minimal pairs of $\mathrm{H}-\mathrm{L}$ contrast. The inter-stimulus interval was $200 \mathrm{~ms}$. A two-alternative forced-choice procedure was used throughout. The subjects were presented with a single auditory stimulus while a pair of photographs evoking the referents of the minimal pair for tone were displayed simultaneously alongside on a paper sheet. The subjects were instructed to respond by pressing one of two keys of a portable computer covered with colored paper, a blue key if the auditory stimulus corresponded to the visual stimulus on the right side of the paper sheet, and a red key if the auditory 
stimulus corresponded to the visual stimulus on the left side of the paper sheet. No feedback was given. To monitor the subjects' attention and engagement in the experiment, one visual stimuli pair involving the contrast between a high and a falling tone was included as a foil stimuli ( $w a j j$ 'log', wâj 'papaya'). For this pair, the auditory stimuli presented to the subjects were a high tone word and a low tone word instead of the falling one. The form wàj with low F0 is a meaningless word. The experiments were introduced to the subjects by instructions in their native language. Before the experimental trials, the subjects were presented with the series of individual visual stimuli and asked to pronounce the respective words. The purpose of this preparation task was to ensure the recognition of the minimal pairs intended. Before the experimental trials began, the participants completed a practice session. Each subject was tested individually. The audio stimuli were delivered through noise canceling headphones and the experiment was carried out in a quiet room so that ambient noise conditions could not interfere with the experiment. The experiment lasted between 20 and 25 minutes, depending on the time consumed in the practice trials. The experiment was performed after the subject was familiar with and confident about the task. Stimuli and data were presented, collected, recorded and processed on a portable computer by using the Praat program. After the experiment was finished subjects were asked to informally judge how many different voices and their sex they have heard pronouncing the prompt sentences and the target words. This task was designed to show whether the subjects had uncounsciously considered the frequencies of the sentences as a variable surrounding context in terms of the voice source of the sitmuli, whereas the target word was considered as produced from only one voice.

\section{HYPOTHESES}

The study reported here asks whether the frequency of the context can influence the perception of pitch of phonemic tone. It was hypothesized that if the surrounding context exerts influence in how subjects perceive the tones, a high tone word will have better rates of identification in a low frequency setting, but it might have impoverished rates in a high frequency context. The opposite trend is predicted for low tone words. This hypothesis is complementary to the hypothesis in which identification of tone would be the same regardless of the frequency of adjacent contexts. A secondary topic of research is the pattern of perception between high and low tones. The central question here is to see whether there are intrinsec differences in the pattern of recognition of the two tones. However, since there is no phonological evidence of markedness relationships between the phonemic tones of $\mathrm{YZ}$ nor are previous experimental studies grounding a line of inquiry, no predictions or hypotheses have been formulated in advance on this regard, hence, 
the findings will be incorporated as a posteriori interpretation of the results.

\section{RESULTS}

The percentage of the identification function pooled across subjects is shown in Figure 4. The figure shows the percentage of responses labeled as "High" and "Low" tone along the seven points in the continuum going from the prompt sentence with the highest frequency (stim 1) to the one with the lowest one (stim 7).

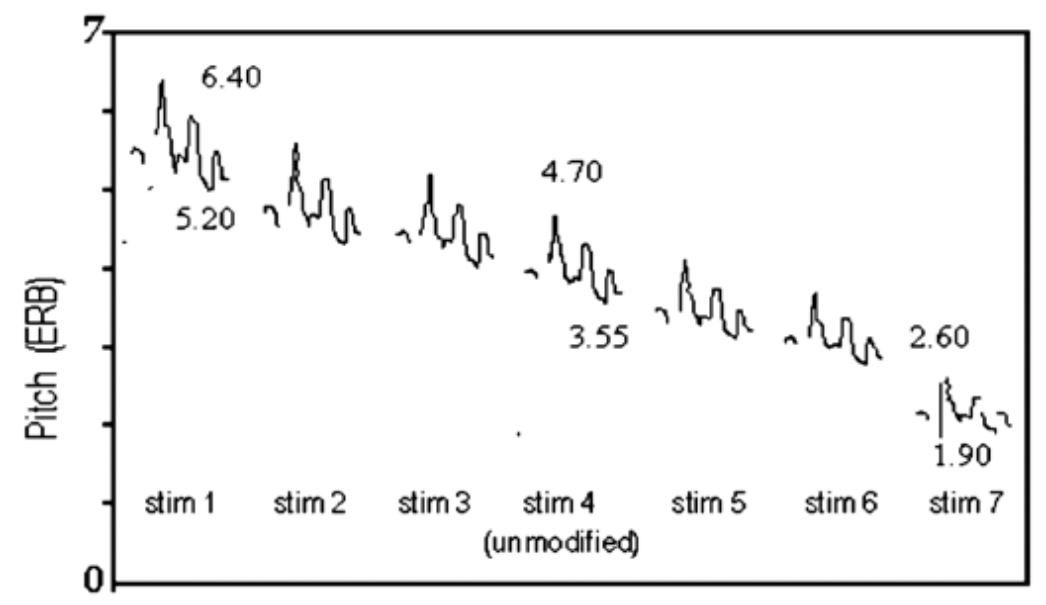

Figure 3. Pitch tracks of the seven versions of the sentence Bnèchj bi dìllên yèlò' gànà' 'Guess what word did you hear here' used to prompt each of the words illustrating canonical minimal pairs of tone in $\mathrm{YZ}$.

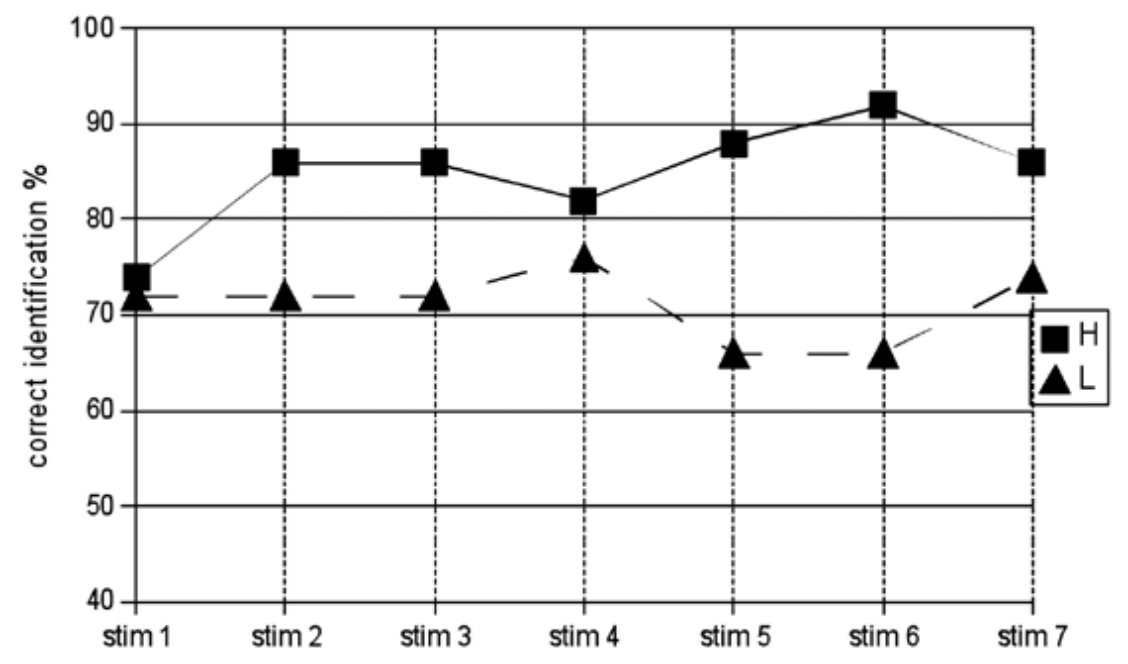

Figure 4. Across subjects identification of high and low tone words as a function of the frequency of the prompt sentence from the highest stimulus (1) to the lowest (7). 
The results show that listeners' pitch judgments of high and low tone words do not appear to be determined by the frequency of the auditory context in which they occur. As shown in the figure, the subjects correctly identified the high and low tones across the continuum. Nevertheless, the graph also shows tendencies suggesting some influence, albeit modest, of the adjacent frequencies in identifying the tones. On the one hand, the correct identification of a high tone word was enhanced when it occurred surrounded by a low pitch context, the highest rate for a $\mathrm{H}$ tone word occured after sentences with an overall low frequencies (88 and $92 \%$ for stimuli 5 and 6 , respectively). In contrast, a high pitch context seems to reduce the correct identification of a high tone word. Accordingly, the lowest scores of identification of $\mathrm{H}$ tone words occurs in the context of the prompt sentence with the highest frequency range ( $72 \%$ for stimulus 1$)$. On the other hand, the correct identification of a low tone word was improved in the context of high pitch (stimuli 1,2,3), whereas, the lowest scores of identification occured in low pitch contexts (66\% for both stimuli, 5 and 6 ).

With respect to the effect of the tone of the word on the patterns of identification the results showed a consistent better identification of high than low tone ( $85-71 \%$ respectively). The data was submited to a chi-square (Pearson) test to see whether the differences in the distribution of correct/incorrect response rates for $\mathrm{H}$ and $\mathrm{L}$ tones were significant. The results showed a highly significant global interaction $\chi^{2}=19.181(1, \mathrm{~N}=700), \mathrm{p}=0.0001$.

Further details of the general pattern of identification can be observed at the individual performance. The percentage of responses is summarized in Figure 5. In general, it is comfirmed that high tone is better recognized. However, the results revealed that some subjects ( $\mathrm{f} 1, \mathrm{f} 2, \mathrm{f} 3, \mathrm{f} 7$ and $\mathrm{m} 3$ ) are equally able at recognizing both tones, whereas others are more sensitive to the high-low distinction of the word ( $\mathrm{f} 4, \mathrm{f5}, \mathrm{f} 6, \mathrm{~m} 1$ and $\mathrm{m} 2$ ). The figure also shows that although low tone words are correctly recognized by most of the subjects, there is a trend to a less accurate identification of this tone, as compared with the identification of high tone words. This is exemplified by the pattern found in subjects $\mathrm{f} 4$ and $\mathrm{m} 1$ who obtained scores close to chance (correct $\mathrm{L}=57 \%$ ), and the extreme case of subject f5 who incorrectly identified more than half of the low tone words as high (51\%). Nonetheless, their respective identification of $\mathrm{H}$ tone is correct $(\mathrm{H}=77$ and $74 \%)$, and in the case of $\mathrm{f} 5$ is close to perfect (94\%). 


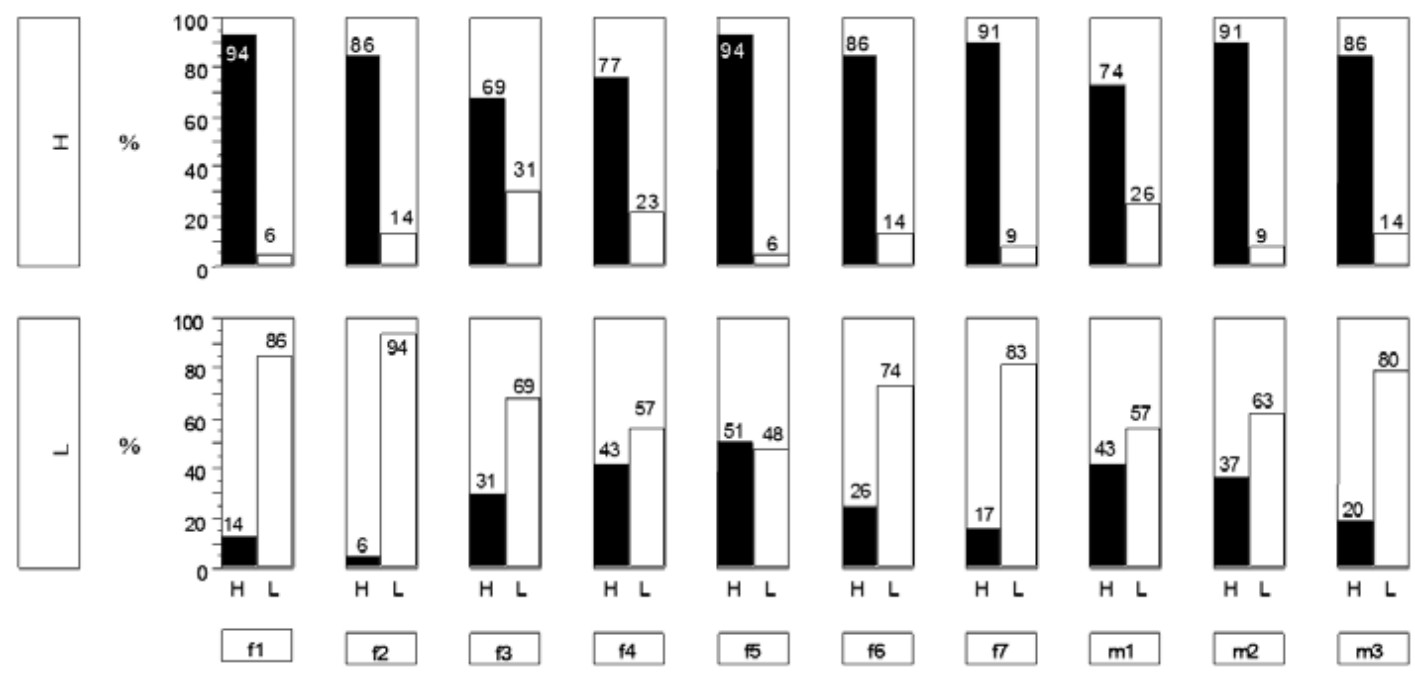

Figure 5. Individual scores of correct identification of high and low tones words.

To further test whether the low or high frequencies of the antecedent sentence had an effect on the identification of the tone words, the data was divided in three stimuli subsets: a) One group was composed of the three sentence stimuli of higher frequencies than that of the naturally produced sentence (stimuli 1, 2 and 3, labeled as 'stim<4'); b) A second group formed by the sentence stimuli of lower frequencies than that of the naturally produced sentence (stimuli 5, 6 and 7, labeled as 'stim>4'), and c) A singleton representing the naturally spoken sentence ('stim 4 ' in the table). The counts, percentages of correct and incorrect identification of $\mathrm{H}$ and $\mathrm{L}$ tones and the corresponding significance levels are summarized in Table I. Just like in the overall results, there was no significant effect of the prompt sentence stimuli in the distribution of correct/incorrect responses, nor there was an interaction with the tone of the word. Instead, an effect of the tone of the word was revealed: even though both tones are well identified, $\mathrm{H}$ tone words were significantly better identified when the tones of the prompt sentence were lower than the unmodified sentence, $\chi^{2}=4.235(1, \mathrm{n}=300), \mathrm{p}=0.040$ for the subset 'stim $<4$ ', and $\chi^{2}=17.876(1, \mathrm{n}=300), \mathrm{p}=0.0001$ for the subset 'stim $>4$ '. In contrast, the results did not reveal a significant difference in the identification of $\mathrm{H}$ and $\mathrm{L}$ when the stimuli was 'stim $=4$ ', the naturally produced sentence, $\chi^{2}=$ $0.542(1, \mathrm{n}=100), \mathrm{p}=0.461$.

The variation in the performance of the subjects considering the continuum of the sentence stimuli confirms the general findings. Table II summarizes the individual results. The distribution confirms that some subjects have a good performance at identifying tone overall $(\mathrm{f} 1, \mathrm{f} 2, \mathrm{f} 7, \mathrm{~m} 3)$, whereas others are less apt at the task ( $\mathrm{f} 3, \mathrm{f} 4$ and $\mathrm{m} 1$ ). The data shows that some individuals are more sensitive to the high-low distinction of the word (f4, f5, f6, $\mathrm{m} 1, \mathrm{~m} 2$ ). An identification 
enhancement effect was observed in a group of subjects ( $\mathrm{f} 4, \mathrm{f} 6$ and $\mathrm{m} 3$ ), i.e. there was an improved identification of the target word in a context that makes the target word more salient ( $\mathrm{H}$ tone words after low pitch sentences and $\mathrm{L}$ tone words after high pitch sentences). Nonetheless, some subjects showed the opposite effect to enhancement, i.e. their perception of the tone of the target word in the context of a sentence of an alike frequency was improved. For instance, the scores of $\mathrm{L}$ tone words for subject $\mathrm{f} 3$ improved in the context of low pitch sentences. At this point it is important to mention that the two effects are independent of each other. Subject f4, for example, showed an enhanced identification of $\mathrm{H}$ in low frequency contexts (stimuli 5, 6 and 7); however, the corresponding expected relationship, a better identification of $\mathrm{L}$ embedded in a high frequency context was not observed. Finally, one subject $(\mathrm{m} 1)$ showed a pattern that is inconsistent with the dependent factor of the experiment, namely, the frequency of the sentence stimuli.

Table I. Effect of the prompt stimuli in the identification of $\mathrm{H}$ and $\mathrm{L}$ tones. Counts, percentages and the corresponding observed significance levels of correct and incorrect identification.

\begin{tabular}{c|c|c|c|c|c|c}
\hline & \multicolumn{2}{|c|}{ stim<4 } & \multicolumn{2}{c|}{ stim=4 } & \multicolumn{2}{c}{ stim $>4$} \\
\hline & $\mathrm{H}$ & $\mathrm{L}$ & $\mathrm{H}$ & $\mathrm{L}$ & $\mathrm{H}$ & $\mathrm{L}$ \\
\hline \multirow{3}{*}{ correct } & 123 & 108 & 41 & 38 & 133 & 103 \\
\cline { 2 - 7 } incorrect & $82 \%$ & $72 \%$ & $82 \%$ & $76 \%$ & $89 \%$ & $69 \%$ \\
\hline$p=$ & 27 & 42 & 9 & 12 & 17 & 47 \\
\cline { 2 - 7 } & $18 \%$ & $28 \%$ & $18 \%$ & $24 \%$ & $11 \%$ & $31 \%$ \\
\hline
\end{tabular}

The individual data were submited to a chi-square test. Sentence stimuli was divided in the same three subsets as in Table I to show the effect of the context in the identification of tone. Table III shows the summary of the results. It was confirmed that, in general, the subjects correctly identify both $\mathrm{H}$ and $\mathrm{L}$ tones. However, a better identification of $\mathrm{H}$ tone words proved to be significant only for subjects $\mathrm{f5}$ ( $\mathrm{stim}<4$ and stim>4), $\mathrm{f} 4, \mathrm{f6}$ and $\mathrm{m} 2$ (the latter three in the contexts of low frequency sentences, stim $>4$ ). The data was further analyzed through a series of logit models looking for the interaction and effects between the prompt stimuli and the tone of the words ${ }^{1}$. The results showed that the effect of the context was non-significant overall, but only for subjects $\mathrm{f} 5(\mathrm{p}=0.000363)$ and $\mathrm{m} 2(\mathrm{p}=$ $0.008287)$. The general interaction between the frequencies of the context and the word were barely significant $(\mathrm{p}=0.05709)$, and only significant for one subject f5 $(\mathrm{p}=0.00672)$.

The final task of the experiment sought the subject's perception of the voice

${ }^{1}$ See appendix A for the complete regression output. For comprehensive accounts of the logit model see Agresti (2002), Borooah (2002), Freedman (2005) and Rudas (1998). 
source, i.e. whether the stimuli presented was considered coming from different speakers or from a single one. The findings showed that most of the subjects identified three voices producing the prompt sentences and only two said there were four (f2 and $\mathrm{m} 3$ ). They judged that there were two males and one female, but one said there were two males and two females (f2). All the subjects coincided in identifying only one voice as producing the target words. Some subjects mentioned the peculiar sound of the sentence with the lowest frequency, which, nonetheless, was perceived without problems and considered normal.

Table II. Individual scores (percentage) of correct identification of high and low tone words across the continuum of seven sentences varying in pitch.

\begin{tabular}{|c|c|cccccccc|}
\hline subject & tone & stim 1 & stim 2 & stim 3 & stim 4 & stim 5 & stim 6 & stim 7 \\
\hline f1 & H & 80 & 100 & 100 & 100 & 80 & 100 & 100 \\
& L & 80 & 100 & 80 & 100 & 80 & 60 & 100 \\
\hline f2 & H & 80 & 80 & 100 & 80 & 80 & 80 & 100 \\
& L & 100 & 80 & 100 & 100 & 100 & 100 & 80 \\
\hline f3 & H & 60 & 80 & 60 & 40 & 80 & 80 & 80 \\
& L & 60 & 60 & 80 & 60 & 80 & 80 & 60 \\
\hline f4 & H & 40 & 60 & 80 & 100 & 80 & 100 & 80 \\
& L & 80 & 20 & 60 & 60 & 40 & 40 & 100 \\
\hline f5 & H & 80 & 100 & 100 & 80 & 100 & 100 & 100 \\
& L & 60 & 60 & 40 & 40 & 20 & 60 & 60 \\
\hline f6 & H & 100 & 60 & 100 & 60 & 80 & 100 & 100 \\
& L & 100 & 60 & 80 & 100 & 80 & 40 & 60 \\
\hline f7 & H & 80 & 100 & 100 & 100 & 100 & 80 & 80 \\
& L & 60 & 80 & 80 & 100 & 60 & 100 & 100 \\
\hline m1 & H & 40 & 100 & 60 & 80 & 100 & 80 & 60 \\
& L & 40 & 80 & 60 & 60 & 60 & 60 & 40 \\
\hline m2 & H & 100 & 100 & 80 & 100 & 100 & 100 & 60 \\
& L & 80 & 80 & 60 & 60 & 80 & 40 & 40 \\
\hline m3 & H & 80 & 80 & 80 & 80 & 80 & 100 & 100 \\
& L & 60 & 100 & 80 & 80 & 60 & 80 & 100 \\
\hline
\end{tabular}

Table III. Effect of the context in the identification of tone.

\begin{tabular}{|c|c|c|c|c|c|c|c|c|c|c|}
\hline & \multicolumn{10}{|c|}{ stim<4 } \\
\hline & f1 & f2 & f3 & $\mathrm{f} 4$ & f5 & f6 & $\mathrm{f7}$ & $\mathrm{m} 1$ & $\mathrm{~m} 2$ & m3 \\
\hline value & 0.370 & 0.370 & 0.000 & 0.136 & 6.136 & 0.240 & 2.160 & 0.144 & 2.160 & 0.000 \\
\hline \multirow[t]{3}{*}{$p=$} & 0.543 & 0.543 & 1.000 & 0.713 & 0.013 & 0.624 & 0.142 & 0.705 & 0.142 & 1.000 \\
\hline & \multicolumn{10}{|c|}{ stim $=4$} \\
\hline & f1 & f2 & f3 & $\mathrm{f} 4$ & f5 & f6 & $\mathrm{f} 7$ & $\mathrm{~m} 1$ & $\mathrm{~m} 2$ & m3 \\
\hline value & * & 1.111 & 0.400 & 2.500 & 1.667 & 2.500 & * & 0.476 & 2.500 & 0.000 \\
\hline \multirow[t]{3}{*}{$p=$} & * & 0.292 & 0.527 & 0.114 & 0.197 & 0.114 & * & 0.490 & 0.114 & 1.000 \\
\hline & \multicolumn{10}{|c|}{ stim $>4$} \\
\hline & $\mathrm{f} 1$ & $\mathrm{f} 2$ & f3 & f4 & f5 & f6 & $\mathrm{f7}$ & $\mathrm{m} 1$ & $\mathrm{~m} 2$ & m3 \\
\hline value & 1.154 & 0.370 & 0.186 & 2.727 & 10.909 & 4.658 & 0.000 & 2.400 & 3.968 & 1.154 \\
\hline$p=$ & 0.283 & 0.543 & 0.666 & 0.099 & 0.001 & 0.031 & 1.000 & 0.121 & 0.046 & 0.283 \\
\hline
\end{tabular}




\section{DISCUSSION}

The present study examined whether the pitch of a larger context provided by a prompt sentence can influence the recognition of tone words in YZ. The results obtained revealed that the frequency of the surrounding speech context in which a word is heard does not determine its correct identification. The broader implication of this finding is that $\mathrm{YZ}$ listeners have the ability to segregate the different speech sources that they are exposed to, store them in memory and recognize the various characteristics of each source. The design used in this study provided the suitable experimental conditions to support this claim: subject's attention was deliberately directed to the target word, whereas the changing stimuli (i.e. the prompt sentences) were intended to be suppressed form their focus of attention. Despite of this, subjects systematically judged that the prompt stimuli were produced by different speakers, but a single voice was heard pronouncing the tone words, which furthermore, were appropriately recognized. The conditions of an experimental setting as the present study are admittedly a simplification of the complex auditory task that a listener is exposed to in a customary situation; nevertheless, it is quite possible that $\mathrm{YZ}$ listeners had employed the same heuristics that they use in natural environments to identify individual characteristics of the voices that they have heard, keep them in memory and normalize their acousticphonetic variation. In that sense, the present findings are in line with increasing research demonstrating the significance of working memory in language acquisition (Gathercole, 1999; Papagno, Valentine and Baddeley, 1991), as well with the several studies showing the relevance of pitch to discriminate voices (Brokx and Nooteboom, 1982; Culling and Darwin, 1993), and other findings indicating that there are normalization mechanisms mediating processes of word recognition and lexical access (Leather, 1983; Mullennix, Pisoni and Martin, 1989; Mullennix and Pisoni, 1990).

The present study also investigated whether there were differences in the pattern of recognition of high and low tones. The results showed a consistent correct identification for high and low tone words; however, there was a better identification of high than low tone words. This pattern might be explained by a greater relative subjective strength of high frequency percepts over the low frequeny stimuli. Psychoacostic research has found that for pure tone sequences the higher-frequency components of the sequences were perceptually more salient than lower-frequency ones (Spiegel and Watson; 1981, Watson, Wroton, Kelly and Benbassat, 1975; Watson, 1976; Watson, Kelly and Wroton, 1976; Divenyi and Hirsh, 1978). The results obtained here are consistent with these findings and allow us to propose an explanation: as high pitch is perceptually more prominent than low pitch, the chances of not noticing a high tone word are lower than a low tone word, which, in turn, would be less salient, and therefore, more easily 
missperceived. It is relevant to mention that a production study of YZ (Avelino, 2005) showed that the three tones are equally stable in terms of their slant and distribution in the F0 space, and more importantly, that other potentially redundant acoustic-phonetic cues, such as duration or phonation type that could assist the perception of the tones, were not signicantly different. Specifically, the stimuli target words had prevocalic voiced consonants which induced almost identical rising F0 perturbations for both high and low tone words. The average difference between the corresponding slopes of each pair was $2.2 \mathrm{~Hz}$. A previous study investigating the perception of tone in YZ (Avelino, 2003) showed that within a threshold of tone sensitivity of $15 \mathrm{~Hz}$ high and low tones are tolerated as plausible exemplars of their respective categories. The F0 perturbations observed in the stimuli used in the present study clearly are well below this threshold. Together, the almost identical variation in pitch and the similar trajectory produced by consonantal effects suggest that F0 perturbations could not cue the identificaty of the tone. The other commonly mentioned feature that might cue tone identification is intensity; however, a confounding effect produced by this feature was prevented in the preparation of the experiment as intensity values for all the stimuli were uniform. Therefore, the findings about the patterns of tone perception could not be derived directly from other concomitant acoustic properties to tone production.

The individual results revealed further details in the recognition pattern of tone words. In spite of the fact that most of the subjects correctly recognized the tone of the words, there was an asymmetrical trend, although overall subtle, with respect to the sentence stimuli continuum. The results indicate that some subjects had a tendency to contextual enhancement in the identification of high and low tone, in a pattern that is inversely related to the frequency of the prompt sentence.

Considered together, it appears that the results obtained are in contradiction to each other: On the one hand, there is a correct identification of tone-words (high and low), regardless of the surrounding context. On the other, there is an indication of a facilitatory influence of context in the recognition of the tones. Rather than disregard the less reliable finding, and consider only the unquestionable result, it seems more germane to a more judicious understanding of the phenomenon of pitch perception to formulate a hypothesis that integrates the two findings. The hypothesis advanced here considers that the two types of seemingly antagonistic results reflect differences in the time domain of memory-related processing of speech. On the one hand, in a short time window, inhibitory responses of a particular frequency surrounded in the broader context of a different frequency could make the auditory nerve fibers sensitive to the contrast between the two frequencies rather than absolute values associated to characteristic frequencies (in analogous way to the visual lateral inhibition effect) (Cariani and Delgutte, 1997; Gulick, Gescheider and Frisina, 1989; Schouten, 1987; Zwicker and Fastl, 1990). 
The acoustic-auditory information thus obtained does not require conscious attention and it is stored primarily in our sensory memory (Szymanski, Yund and Woods, 1999). Presumably, a contextual enhancement effect could have been produced at this stage. On the other hand, in a longer time window, the analysis of the whole auditory scene is completed and the information compiled in "declarative memory" ((Bregman, 1990; Tulving \& Schacter, 1990). At this stage, pragmatic (gender's voice, attitude, etc.) and encyclopedic information (lexicon, phonological, semantic specification) is retrieved. It is likely that the results obtained showing a perceptual constancy effect as indicated by the judgments of different voice types and the accurate recognition of high and low tone words could have happened at this stage. This hypothesis is further supported by recent research showing that there are separate memory-related process for frequencies and auditory patterns that depend on the perceptual context (Alain, Achim and Woods; 1999).

\section{CONCLUSIONS}

The perception of the acoustic world surrounding us very often is different from its physical properties. Our mental representation of the sounds that we are exposed to are not in a one to one correspondence with the sounds we sense, but are the product of ecological and evolutionary processes. Particular situations and scenes give prominence to certain features; in this manner, the auditory objects and their environements are categorized and loaded in memory so that recognition of complex dynamic scenes are perceived optimally. In particular, recognition and categorization of voice is a fundamental skill of humans. Precise identification of voices and linguistic objects (sentences, words, phonemes, etc.) are crucial for effective communication. However, the normal context of hearing contains multiple, competing and noisy sources. In such disadvantageous conditions the identity of the percepts is more efficient if they are stored in memory. The results of the present study suggest that high-level cognitive processes such as attention might constrain basic auditory mechanisms involved in identifying the phonemic tone in a language to guarantee perceptual constancy. Nevertheless, the results showing a better identification of tones in context that is inveresely proportional to their frequency supports the idea that peripheral auditory processing may enhance the correct identification of the tones by a general function of contrast. 


\section{REFERENCES}

Adelson, E. H. 1993. "Perceptual organization and the judgment of brightness". Science, 262, pp. 2042-2044.

Agresti, Alan. 2002. Categorical data analysis. Second edition. New York: Wiley.

Alain, Claude, Andre Achim and David L. Woods. 1999. "Separate MemoryRelated Processing for Frequency and Auditory Patterns". Psychophysiology, 36, pp. 737-744.

Avelino, Heriberto. 2003. Categorical perception of phonemic tone in Yalálag Zapotec. International Congress of Phonetic Sciences, Barcelona, España.

Avelino, Heriberto. 2005 (submitted). The phonetics and phonology of nonmodal phonation variability in Yalálag Zapotec, International Journal of American Linguistics.

Boersma, Paul \& Weenink, David. 2005. Praat: doing phonetics by computer (Version 4.3.17) [Computer program]. Retrieved May, 2005, from http:// www.praat.org/.

Borooah, Vani Kant. 2002. "Logit and probit: Ordered and multinomial models". Quantitative applications in the social sciences, Vol. 138.

Bregman, Albert S. 1990. Auditory scene analysis. The perceptual organization of sound. Cambridge, MA: MIT Press.

Brokx, J. P. L. and S. G. Nooteboom. 1982. "Intonation and the perceptual simultaneous voices". Journal of Phonetics, 10, pp. 23-36.

Cariani, Peter A. and Betrand Delgutte. 1997. "Auditory Neural Processing of Speech". The Handbook of Phonetic Sciences. Edited by W.J. Hardcastle and J. Laver. Oxford: Blackwell.

Culling, J. E. and Darwin. C. J. 1993. "The role of timbre in the segregation of simultaneous voices with intersecting F0 contours". Perception and Psychophysics, 34, pp. 303-309.

Divenyi, P. L. and I. J. Hirsh. 1978. "Some figural properties of auditory patterns". Journal of the Acoustical Society of America, 64, pp. 1369-1385.

Fowler, C. A., and D. J. Dekle. 1991. "Listening with eye and hand: Cross-modal contributions to speech perception". Journal Experimental Psychology: Human Perception and Performance, 17, pp. 816-828.

Freedman, David. A. 2005. Statiscal models: Theory and practice. Cambridge University Press.

Gathercole, Susan E. 1999. "Cognitive Approaches to the Development of ShortTerm Memory. Trends in Cognitive Sciences, 3, 11(32), pp. 410-419.

Grosjean, F. 1980. "Spoken word recognition processes and the gating paradigm". Perception and Psychophysics, 28, pp. 267-283.

Gulick, W.L., G.A. Gescheider and R.D. Frisina. 1989. Hearing: Physiological Acoustics, Neural Coding, and Psychoacoustics. Oxford: Oxford University Press. 
Hartline, Haldan Keffer. 1967. Visual receptors and retinal interaction. Nobel Lecture, December 12, 1967. Retrieved from http://nobelprize.org/medicine/ laureates/1967/hartline-lecture.pdf.

Hartline, Haldan Keffer, H.G. Wagner and Floyd Ratcliff. 1956. "Inhibition in the Eye of Limulus". Journal of General Physiology, 39:5, pp. 651-673.

Holt, L. L. and A. J. Lotto. 2002. "Behavioral examinations of the neural mechanisms of speech context effects". Hearing Research, 167, pp. 156-169.

INEGI. 2001. XII censo general de población y vivienda, 2000. Perfil sociodemográfico. México. Aguascalientes, Ags.: Instituto Nacional de Estadística, Geografía e Informática.

Ladefoged, Peter. 1989. "A note on 'Information conveyed by vowels" ". Journal of the Acoustical Society of America, 85, pp. 2223-2224.

Ladefoged, Peter and Donald. E. Broadbent. 1957. "Information conveyed by vowels". Journal of the Acoustical Society of America, 29, pp. 98-104.

Leather, J. 1983. "Speaker normalization in perception of lexical tone", Journal of Phonetics, 11, pp. 373-382.

Lotto, A.J. and K.R. Kluender. 1998. "General contrast effects in speech perception: Effect of preceding liquid on stop consonant identification". Perception and Psychophysics, 60, pp. 602.

Lotto, A. J., S. C. Sullivan and L. L. Holt. 2003. "Central locus for non-speech context effects on phonetic identification". Journal of the Acoustical Society of America, 113, pp. 53-56.

Massaro, D.W. 1987. Speech Perception by Ear and by Eye: A Paradigm of Psychological Inquiry. Hillsdale, N.J: Erlbaum.

McGurk, H. and J. MacDonald. 1976. "Hearing lips and seeing voices", Nature, 264, pp. 746-748.

Mullennix, John W., D. B. Pisoni and C. S. Martin. 1989. "Some effects of talker variability on spoken word recognition". Journal of the Acoustical Society of America, 85, pp. 365-378.

Mullennix, John.W., and D. B. Pisoni. 1990. "Stimulus variability and processing dependencies in speech perception". Perception and Psychophysics, 47, pp. 379390.

Papagno, C., T. Valentine and A. Baddeley. 1991. "Phonological short-term memory and foreign-language vocabulary learning". Journal of Memory and Language, 30, pp. 331-347.

Rudas, Tamás. 1998. Odds ratios in the analysis of contingency tables. Thousand, Oaks, CA: Sage Publications. Quantitative Applications in the Social Sciences Series No. 119.

Schouten, M. E. H. (ed.). 1987. The psychophysics of speech perception. Dordrecht: M. Nijhoff Publ.

Spiegel, M. F. and C. S. Watson. 1981. "Factors in the discrimination of tonal 
patterns. III. Selective attention and the level of target tones". Journal of the Acoustical Society of America, 69, pp. 223-230.

Szymanski, M. D., E.W. Yund and D. L. Woods. 1999. "Human brain specialization for phonetic attention". NeuroReport, 10, pp. 1605-1608.

Tulving, Endel \& Schacter, Daniel. L. 1990. "Priming and human memory systems". Science, 247, pp. 301-306.

Warren, R. M., and R. P. Warren. 1970. "Auditory illusions and confusions". Scientific American, 223, pp. 30-36.

Watson, Charles S. 1976. "Factors in the discrimination of word-length auditory sequences". Hearing and Davis: Essays Honoring Hallowell Davis, edited by S. K. Hirsh, D. H. E., I. J. Hirsh and S. R. Silverman. Washington University Press, St. Louis, pp. 175-189.

Watson, Charles S., H. W. Wroton, W. J. Kelly and C. A. Benbassat. 1975. "Factors in the discrimination of tonal patterns. I. Component frequency, temporal position, and silent intervals". Journal of the Acoustical Society of America, 57, pp. 1175-1185.

Watson, Charles. S., W. J. Kelly and H. W. Wroton. 1976. "Factors in the discrimination of tonal patterns. II. Selective attention and learning under various levels of stimulus uncertainty". Journal of the Acoustical Society of America, 60, pp. 1176-1187.

Zwicker, E. and H. Fastl. 1990. Psychoacoustics. Berlin: Springer.

\section{APPENDIX A}

Regression tables for the three logit models tested.

\section{CONTEXT AND INTERACTION}

\begin{tabular}{|l|c|c|c|c|}
\hline & Estimate & Std. Error & z value & $\operatorname{Pr}(>|z|)$ \\
\hline Intercept & 1.4800 & 0.4900 & 3.0100 & $0.00263^{* *}$ \\
\hline f1 & 0.4056 & 0.6400 & 0.6300 & 0.5300 \\
\hline f2 & 1.4174 & 0.8400 & 1.6800 & 0.0900 \\
\hline f3 & -0.6064 & 0.5600 & -1.0900 & 0.2800 \\
\hline f4 & -1.0991 & 0.54000 & -2.0200 & $0.04314^{*}$ \\
\hline f5 & -1.4441 & 0.54137 & -2.6700 & $0.00764^{* *}$ \\
\hline f6 & -0.3255 & 0.5700 & -0.5700 & 0.5700 \\
\hline f7 & 0.1893 & 0.6200 & 0.3100 & 0.7600 \\
\hline m1 & -1.1000 & 0.5400 & -2.0200 & $0.04314^{*}$ \\
\hline m2 & -0.86000 & 0.54870 & -1.56800 & 0.11680 \\
\hline m3 & NA & NA & NA & NA \\
\hline f11 & 0.36000 & 0.95094 & 0.37900 & 0.70446 \\
\hline
\end{tabular}


RLA. Revista de Lingüística Teórica y Aplicada, 48 (1), I Sem. 2010

\begin{tabular}{|l|c|c|c|c|}
\hline & Estimate & Std. Error & z value & $\operatorname{Pr}(>|z|)$ \\
\hline f21 & -1.67021 & 0.95348 & -1.75200 & 0.07983 \\
\hline f31 & -0.67321 & 0.64676 & -1.04100 & 0.29793 \\
\hline f41 & 0.26333 & 0.65312 & 0.40300 & 0.68681 \\
\hline f51 & 2.21041 & 0.88499 & 2.49800 & $0.01250 *$ \\
\hline f61 & 0.07270 & 0.72613 & 0.10000 & 0.92025 \\
\hline f71 & 0.13824 & 0.84124 & 0.16400 & 0.86947 \\
\hline m11 & 0.10528 & 0.64469 & 0.16300 & 0.87028 \\
\hline m21 & 1.18811 & 0.79000 & 1.50000 & 0.13373 \\
\hline m31 & -0.25284 & 0.74605 & -0.33900 & 0.73468 \\
\hline context & -0.02307 & 0.06203 & -0.37200 & 0.70992 \\
\hline interaction & 0.17232 & 0.10001 & 1.72300 & 0.08487 \\
\hline
\end{tabular}

CONTEXT, NO INTERACTION

\begin{tabular}{|c|c|c|c|c|}
\hline & Estimate & Std. Error & z value & $\operatorname{Pr}(>|z|)$ \\
\hline (Intercept) & $1.21 \mathrm{E}+000$ & $4.63 \mathrm{E}-001$ & 2.61800 & $0.008836^{* *}$ \\
\hline f1TRUE & $4.06 \mathrm{E}-001$ & $6.42 \mathrm{E}-001$ & 0.63200 & 0.52731 \\
\hline f2TRUE & $1.42 \mathrm{E}+000$ & $8.42 \mathrm{E}-001$ & 1.68400 & 0.09220 \\
\hline f3TRUE & $-6.07 \mathrm{E}-001$ & $5.58 \mathrm{E}-001$ & -1.08700 & 0.27683 \\
\hline f4TRUE & $-1.10 \mathrm{E}+000$ & $5.44 \mathrm{E}-001$ & -2.02400 & $0.043011^{*}$ \\
\hline f5TRUE & $-1.45 \mathrm{E}+000$ & $5.42 \mathrm{E}-001$ & -2.66900 & $0.007602^{* *}$ \\
\hline f6TRUE & $-3.26 \mathrm{E}-001$ & $5.73 \mathrm{E}-001$ & -0.56800 & 0.56971 \\
\hline f7TRUE & $1.90 \mathrm{E}-001$ & $6.17 \mathrm{E}-001$ & 0.30700 & 0.75863 \\
\hline m1TRUE & $-1.10 \mathrm{E}+000$ & $5.44 \mathrm{E}-001$ & -2.02400 & $0.043011^{*}$ \\
\hline m2TRUE & $-8.62 \mathrm{E}-001$ & $5.49 \mathrm{E}-001$ & 0.00000 & 0.11658 \\
\hline m3TRUE & NA & NA & NA & NA \\
\hline f11 & $1.01 \mathrm{E}+000$ & $8.74 \mathrm{E}-001$ & 1.15800 & 0.25000 \\
\hline f21 & $-1.01 \mathrm{E}+000$ & $8.74 \mathrm{E}-001$ & -1.15800 & 0.24684 \\
\hline f31 & $1.19 \mathrm{E}-016$ & $5.15 \mathrm{E}-001$ & $2.31 \mathrm{E}-016$ & 1.00000 \\
\hline f41 & $9.30 \mathrm{E}-001$ & $5.28 \mathrm{E}-001$ & 1.76100 & 0.07829 \\
\hline f51 & $2.86 \mathrm{E}+000$ & $8.03 \mathrm{E}-001$ & 3.56600 & $0.000363{ }^{* * *}$ \\
\hline f61 & $7.32 \mathrm{E}-001$ & $6.19 \mathrm{E}-001$ & 1.18200 & 0.23725 \\
\hline f71 & $7.92 \mathrm{E}-001$ & $7.53 \mathrm{E}-001$ & 1.05300 & 0.29239 \\
\hline m11 & $7.75 \mathrm{E}-001$ & $5.16 \mathrm{E}-001$ & 1.50000 & 0.13367 \\
\hline m21 & $1.84 \mathrm{E}+000$ & $6.98 \mathrm{E}-001$ & 2.64000 & $0.008287^{* *}$ \\
\hline m31 & $4.06 \mathrm{E}-001$ & $6.42 \mathrm{E}-001$ & 0.63200 & 0.52731 \\
\hline context & $4.42 \mathrm{E}-002$ & $4.83 \mathrm{E}-002$ & 0.91500 & 0.35993 \\
\hline & & & & \\
\hline
\end{tabular}


Perceptual constancy and contextual enhancement / H. Avelino

\section{INTERACTION, NO CONTEXT}

\begin{tabular}{|c|c|c|c|c|}
\hline & Estimate & Std. Error & z value & $\operatorname{Pr}(>|\mathrm{z}|)$ \\
\hline (Intercept) & 1.38629 & 0.42258 & 3.28100 & $0.00104^{* *}$ \\
\hline f1TRUE & 0.40547 & 0.64180 & 0.63200 & 0.52754 \\
\hline f2TRUE & 1.41707 & 0.84194 & 1.68300 & 0.09236 \\
\hline f3TRUE & -0.60614 & 0.55781 & -1.08700 & 0.27719 \\
\hline f4TRUE & -1.09861 & 0.54336 & -2.02200 & $0.04319^{*}$ \\
\hline f5TRUE & -1.44345 & 0.54125 & -2.66700 & $0.00766^{* *}$ \\
\hline f6TRUE & -0.32542 & 0.57284 & -0.56800 & 0.56998 \\
\hline f7TRUE & 0.18924 & 0.61621 & 0.30700 & 0.75876 \\
\hline m1TRUE & -1.09861 & 0.54336 & -2.02200 & $0.04319^{*}$ \\
\hline m2TRUE & -0.86020 & 0.54859 & -1.56800 & 0.11687 \\
\hline m3TRUE & $\mathrm{NA}$ & $\mathrm{NA}$ & $\mathrm{NA}$ & $\mathrm{NA}$ \\
\hline f11 & 0.45376 & 0.91685 & 0.49500 & 0.62066 \\
\hline f21 & -1.57697 & 0.91921 & -1.71600 & 0.08624 \\
\hline f31 & -0.58051 & 0.59633 & -0.97300 & 0.33032 \\
\hline f41 & 0.35578 & 0.60376 & 0.58900 & 0.55567 \\
\hline f51 & 2.30268 & 0.84951 & 2.71100 & $0.00672^{* *}$ \\
\hline f61 & 0.16552 & 0.68135 & 0.24300 & 0.80806 \\
\hline f71 & 0.23124 & 0.80260 & 0.28800 & 0.77326 \\
\hline m11 & 0.19773 & 0.59464 & 0.33300 & 0.73949 \\
\hline m21 & 1.28068 & 0.75192 & 1.70300 & 0.08853 \\
\hline m31 & -0.15991 & 0.70231 & -0.22800 & 0.81989 \\
\hline interaction & 0.14925 & 0.07844 & 1.90300 & 0.05709 \\
\hline & & & & \\
\hline
\end{tabular}

